\title{
VAST - a Tool for Recognising Vulnerable Children in the Classroom and Developing a Care Pathway of Intervention
}

\author{
Brian Hall \\ Research Associate, Hartlepool Child \& Adolescent Mental Health Service \\ Dover House, Lynn Street, Hartlepool, TS24 7JZ, England \\ E-mail: brian.hall@nhs.uk \\ Sithy Haddow \\ Research Assistant, Hartlepool Child \& Adolescent Mental Health Service \\ Dover House, Lynn Street, Hartlepool, TS24 7JZ, England \\ E-mail: s1laura@hotmail.com \\ Maurice Place (Corresponding author) \\ Professor of Child \& Family Psychiatry \\ Cheviot House, Northumbria University, Coach Lane Campus \\ Coach Lane, Newcastle/Tyne, NE7 7XA, England \\ E-mail: maurice.place@northumbria.ac.uk
}

\begin{abstract}
The increasing prevalence in young people harming themselves in an area of the North of England stimulated efforts to find ways of reducing this behaviour. The links with stress and poor coping mechanisms prompted this project which sought to explore if prevention strategies could be developed in a younger age group which would reduce the emergence of self harming behaviour, and other maladaptive coping strategies. The preventative intervention focused upon primary schools in the area, and sought to identify and help children who were struggling emotionally on the assumption that they were vulnerable to begin cutting themselves as a way of coping. A specific assessment tool, the Vulnerability Assessment Scale for Teachers (VAST), was developed using teachers' experiences (Dimmock, Grieves, \& Place, 2007), and specifically built around current classroom practice in the UK. In addition a care pathway of intervention was developed and piloted, prior to its more general use in local primary schools.
\end{abstract}

Keywords: Self harm, Coping, Cutting, Resilience, School health service 


\section{Introduction}

The increasing demands and pressures upon children and young people in modern society is reflected in an increasing rate of psychological distress amongst the young (Rutter \& Smith, 1995). In the United Kingdom this has resulted in Government policy seeking to promote child mental health and well-being (e.g. Department of Health, 2000; Department of Education \& Skills, 2004). In trying to achieve this, it has been recognised that liaison and collaboration between all agencies to build upon school staff's understanding of mental health issues is important ( National Committee of Primary Mental Health Services, 2005), because, in part, it helps teachers understand some of the underlying reasons for behaviours that children may exhibit. Such understanding gives a platform from which to shape and direct appropriate services that address the issue of promoting an environment that fosters emotional resilience.

Closer collaboration between agencies also gives the opportunity for specific difficulties to be identified and local solutions found. In one community in the North East of England such a concern arose about the rate of self harm amongst its young people. This prompted a survey of the senior schools in the area which found that $23 \%$ of the young people reported they had cut themselves at least once, with 6.3\% reporting it was something they often did (Hall, Elliott, \& Place, 2009). This rate was higher than the $10 \%$ found in the formal review of cutting behaviour carried out in the United Kingdom by the Mental Health Foundation (2006), and prompted considerable concern in the professional community.

Self harm is one of the patterns of distress that is increasing (Hawton et al., 2003; Klonsky, Oltmanns, \& Turkheimer, 2003), with cutting being the most prevalent method (Ross \& Heath, 2002). The concern of school staff about such behaviour is well documented (Cooke \& James, 2009), and there are protocols to help school staff deal with self harming behaviour when they become aware of it in their school (Shapiro, 2008). This is important because identification and treatment of self-harming behaviours at an early age significantly decreases the risk of the young person attempting suicide. If left untreated, self-harming patients are 30 times more likely to commit suicide than peers who do not practice self-harming behaviour (Roux \& Overcash, 2008).

Self-harm is frequently motivated by the young person's need to avoid what they perceive as a "greater harm" in terms of inner psychic distress (Korner, Gerull, Stevenson, \& Meares, 2007), and tends to emerge around 13 years of age (Favazza \& Conterio, 1988). This association with the stresses that emerge with adolescence, when a young person can easily feel overburdened with insoluble problems (Milnes, Owens, \& Blenkiron, 2002), suggests that part of the attraction of cutting behaviour is its ability to give a great sense of tension release (Rosen \& Collins, 1993). Families are often unaware of the behaviour, and on discovering it report it as being a traumatic experience which makes them feel helpless, prompting them to worry about the possibility of future incidents (Raphael, Clarke, \& Kumar, 2006).

Young people who cut themselves are rarely assessed by professionals unless the cutting is severe. For instance, in one large school based survey in the south of England it was found 
that $6.9 \%$ of adolescents self-harmed either by overdosing or cutting, but only $12.6 \%$ of those were referred to hospital (Hawton, Rodham, Evans, \& Weatherall, 2002). Formal psychiatric evaluation is not however crucial because much of the cutting behaviour occurs without coexisting mental health issues (Cleaver, 2007; Walsh, 2007), and some is clearly linked to the contemporary 'Goth' youth subculture (Young, Sweeting, \& West, 2006).

The fact that in most cases there is a lack of health care involvement presents a significant dilemma in determining how best to intervene. There is evidence that school based programmes to promote positive emotional health are helpful (Kimber, Sandell, \& Bremberg, 2008; Neil \& Christensen, 2009), and that they can help students showing moderate difficulties that may develop into more major mental health problems without intervention (Kolvin et al., 1981; Stallard, Simpson, Anderson, \& Goddard, 2008). Based on such evidence, as one element of the strategy to respond to this behaviour, an emotional health promotion programme was developed with primary schools in the locality to help the teaching staff recognise and intervene with children who appeared vulnerable to future emotional distress, and hopefully reduce future cutting behaviour.

\section{Method (Protocol Development)}

The first element of the protocol development was to develop a screening scale to assess the degree of vulnerability in the pupils that complemented existing teaching practice. This also had the advantage of minimising the amount of disruption the programme would cause to classroom activities.

Work was commenced with a specific primary school which demonstrated particular interest in undertaking a joint approach to developing a programme to reduce children's emotional vulnerability. A core group of 5 teachers were selected by the Head Teacher within the school to work with the project. Using this staff group's experiences and insights of children in the classroom setting, elements of behaviour and emotions which suggested vulnerability were identified and formed into an accessible and easy-to-use screening scale. This work was then shared with the wider teaching population in the school for their views and opinions.

This scale, the Vulnerability Assessment Screening Tool (VAST), draws attention to children's presenting behaviours and uses a likert score to highlight emotions and behaviours that may be of concern. The resulting scale showed good face validity and was piloted within several classes over an 8 month period. Scores from the scale were compared to teacher perceptions with the conclusion that it did not mis-identify any children that were a source of concern to the class teacher. 


\section{Vulnerability Tool}

For each item, please mark the score for Not True, Somewhat True, or Certainly True. It would help us if you give your answers on the basis of the child's behaviour as you see it. If child scores 3 or more in any of the first five areas, undertake in class strategies for no more than 4 weeks.

Child's Name

.Male/Female Date of Birth

Teachers Name

Year Group.

Date.

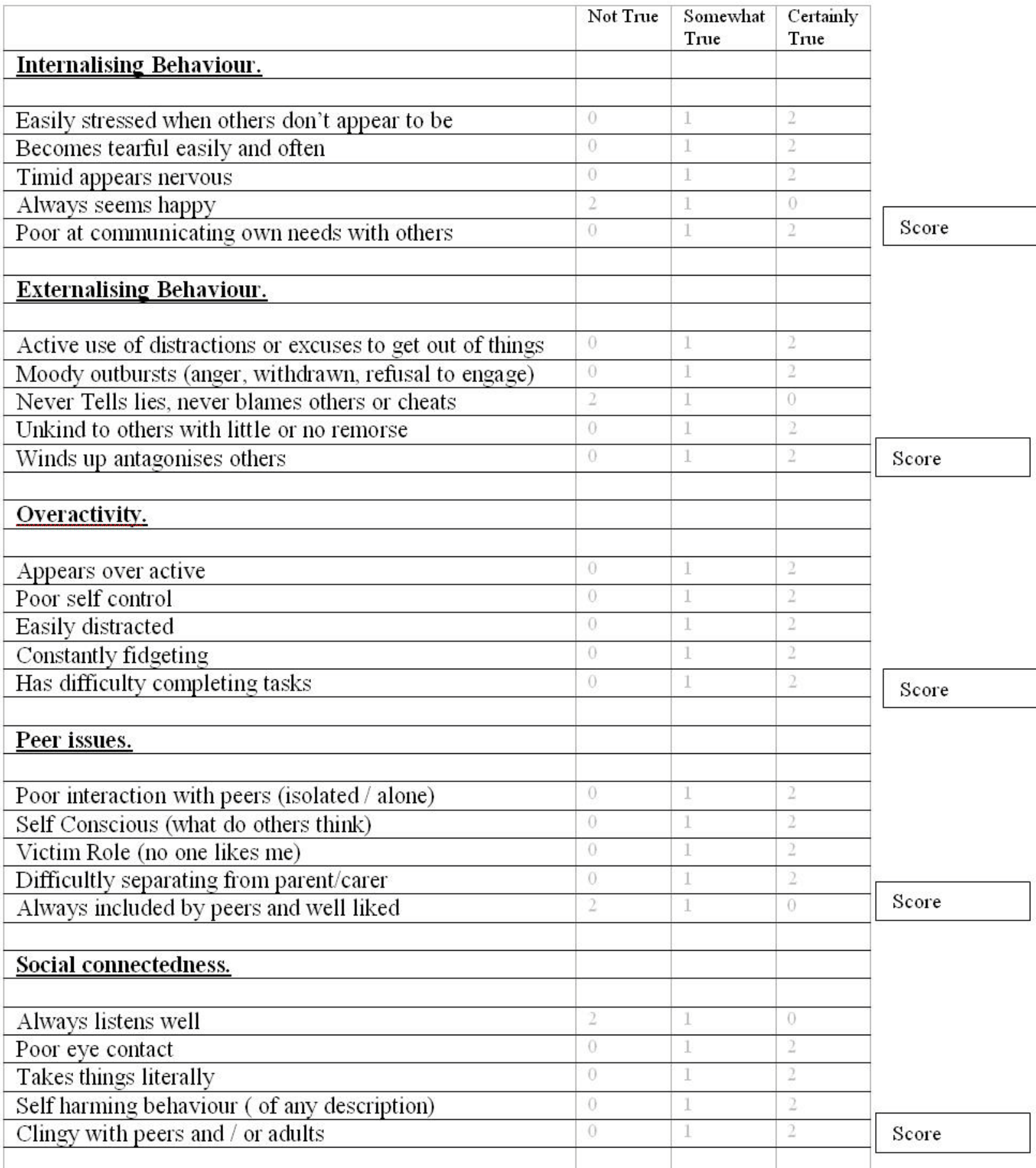




\section{Macrothink}

Opportunities were given to the core group and class room teachers at various points in the piloting phase to discuss any observations they had about using the scale. At the end of the piloting phase a final version was prepared (Figure 1) which saw minor changes to the titling of the behaviour categories, scoring thresholds, and the wording that described some of the behavioural themes.

The second element of the project was to develop a care pathway which sought to use the scale scores to direct intervention and monitor change (Figure 2). The principle driving the protocol was one of incremental increase in intervention, guided at each stage by the child's level of difficulty on each of the categories identified by the screening scale. 


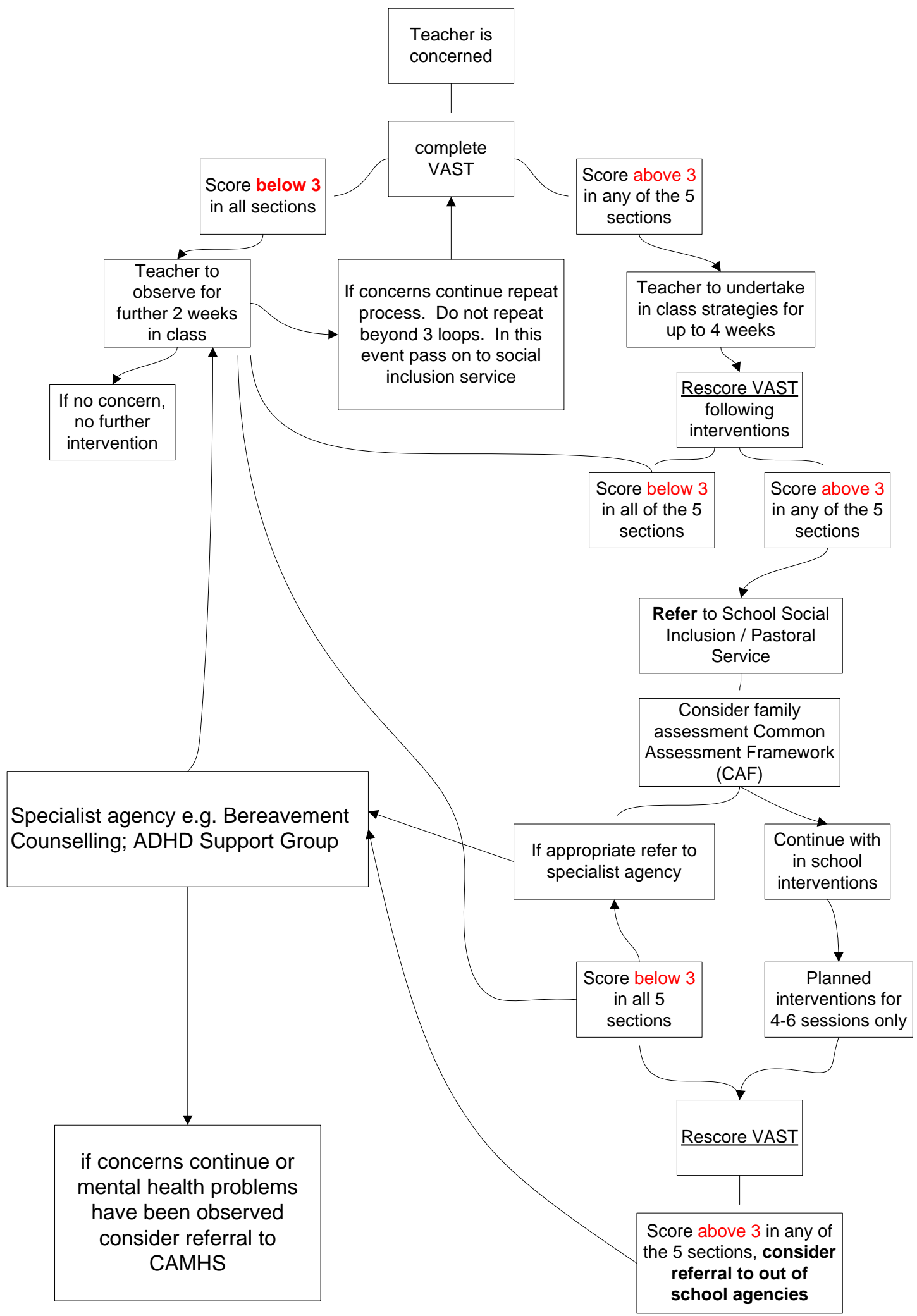

Figure 2. The Care Pathway for Responding to Children with High Vulnerability Scores

The first level of intervention was designated 'In Class Strategies.' Having asked the teaching staff how they would intervene with specific problems their pupils might show, the responses 


\section{Macrothink}

were grouped and the staff asked to institute them on a daily basis for up to a four week

period. The strategies used were:

- $\quad$ Giving lots of reassurance.

- $\quad$ Partner up with positive/caring child.

- $\quad$ Sit closer to teacher in class.

- $\quad$ Give responsibilities such as giving things out, taking register to school head.

- $\quad$ To heighten and praise child's strengths.

- $\quad$ Third party story with moral to the class of caring for one another.

- $\quad$ Offering regular praise.

- $\quad$ Encouraging other children to include child.

- $\quad$ To actively change class seating positions for child to experience others.

- $\quad$ To allow an item (non-noisy) for the child to comfort/fidget with.

- $\quad$ To give succinct, clear and short requests with assuring tones.

- $\quad$ Friendship group work - social skills.

After the intervention the scale was re-scored and if difficulties continued to be significant then the next level of school based intervention was pursued. The use of community based specialist services, such as bereavement counselling, formed the third tier of intervention with referral to the local Child and Adolescent Mental Health Service being the tertiary response.

After the piloting stage the protocol was initially established in four schools, and preliminary development work to introduce it into 32 further schools is underway.

\section{Findings (Protocol Evaluation)}

The initial element of evaluation was undertaken with the staff of the pilot school.

The Head Teacher said he felt the use of this protocol by the whole school could help to validate and measure staffs interventions with children. He also felt it would help him to gather evidence about both the schools and the children's needs. Staff responses were enthusiastic, and their feed-back highlighted that the protocol gave them :

- $\quad$ greater understanding of the child's emotions and behaviours in the classroom.

- $\quad$ The opportunity for any minor difficulties with the child to be identified and resolved in a timely fashion.

- Appropriate and timely referral for the child, including more accurate details from the referrer about their concerns.

- $\quad$ Support and intervention offered by the most appropriate service 'at the time of need.' 
- $\quad$ Increased self-confidence and sociability in the child.

- $\quad$ The programme is resource sensitive and uses the most appropriate service and intervention at the most appropriate time.

\section{Discussion}

School is a setting in which children spend a considerable period of their life (M. Rutter, Maughan, Mortimore, Ouston, \& Smith, 1979) and which can exert very powerful influences upon their emotional development (Easson, 1973). The very universality of school attendance makes it an ideal setting for the early identification and preventative interventions to be delivered, and such interventions are effective not only in increasing psychological well-being among adolescents, but also in decreasing distress, in particular anxiety and somatization (Ruini et al., 2009).

Within the United Kingdom schools are now seen as having a significant role in recognising mental health problems and promoting emotional well-being (Atkinson \& Hornby, 2002). Recently this recognition has begun to find expression through the Government's Social and Emotional Aspects of Learning (SEAL) curriculum resource, which is being made available to all primary and secondary schools in England. However this is a long-term strategy with a general focus and it will take some time to exert an influence on how young people, and particularly young teenagers, are managing their emotional life. For the foreseeable future specific areas of concern will require specific programmes of intervention.

In the case of self-injury, it is a behaviour that, once established, tends to be resistant to treatment efforts (Zila \& Kiselica, 2001), and since only a small proportion of young people who cut are seen by health agencies (Hawton et al., 2002), trying to intervene with this behaviour directly through health agencies is unlikely to be very successful. Self harm protocols to help schools respond to the behaviour are available (Cooke \& James, 2009), but this project is one of the first to try to develop prevention programmes at primary school level.

A key element of the project was to develop a screening tool that was seen as relevant to teaching staff. The scales that are in common use have usually been developed from a general mental health perspective and not with the explicit aim of assisting classroom decisions and interventions. Scales such as the Child Behavior Checklist (Achenbach 1991) and the Strengths \& Difficulties Questionnaire (Goodman 1997) have teacher versions which seek their views of the children's functioning but do not progress the results into classroom advice. This protocol offers the opportunity for school staff to identify a child who is struggling and to intensify the degree of intervention and support offered until the child's functioning has improved sufficiently to no longer prompt concern.

There have been a series of classroom-based, teacher-implemented programmes which have been shown to be effective in preventing mental health difficulties (Rones \& Hoagwood, 2000), but the aim in this project was to produce an escalating programme of intervention which could be imbedded in the routine practice of the school. 


\section{MInstitute ${ }^{\text {Macrothink }}$}

International Journal of Education

ISSN 1948-5476

2009, Vol. 1, No. 1: E10

The VAST scale and its accompanying pathway flow chart appear to form a robust intervention strategy. However the value of the programme does depend upon the motivation and commitment of its users. Lots of encouragement was needed to remind teachers to use this scale throughout the pilot/development period of this study. As well as its potential for increasing resilience it has also been noted that it has helped build a closer working relationship between the specialist Children's Mental Health team and the local schools.

This project illustrates an approach that can be used to respond to local community concerns by determining the parameters of the problem, and then developing specific interventions that are responsive to local needs. This also has the advantage of increasing the sense of collaboration between services, which in itself helps to improve the services offered to young people. The ability of the care pathway to reduce vulnerability, and consequently reduce cutting behaviour will not be known for some time. There is also a cultural dimension to this type of behaviour, and so a reduction in the coming years may be as much to do with changing fads as to the intervention's effectiveness. However promoting emotional resilience in young people is an important goal and pursuing strategies that might achieve this should be a key task for all educators.

\section{Acknowledgements}

We would like to thank the schools that took part in the project for their excellent support. This work was funded by a grant from the United Kingdom Government's Department of Health under the Care Services Improvement Partnership Programme.

\section{References}

Achenbach, T. M. (1991). Integrative Guide to the 1991 CBCL/4-18, YSR, and TRF Profiles. Burlington, VT: University of Vermont, Department of Psychology.

Atkinson, M., \& Hornby, G. (2002). Mental Health Handbook for Schools. London: RoutledgeFalmer.

Cleaver, K. (2007). Characteristics and trends of self-harming behaviour in young people. British Journal of Nursing, 16, 148 - 152.

Cooke, E. A., \& James, V. (2009). A self-harm training needs assessment of school nurses. Journal of Child Health Care, 13, 260 -274.

Department of Education \& Skills (2004). Every Child Matters: next steps. Nottingham: DfES Publications.

Department of Health (2000). Framework for the Assessment of Children in Need and their Families. London: Stationery Office.

Dimmock, M., Grieves, S., \& Place, M. (2007). Young People Who Cut Themselves - A Growing Challenge for Educational Settings. British Journal of Special Education, 35, 42 -48 .

Easson, W. M. (1973). The Severely Disturbed Adolescent. Boston: International University 
Press.

Favazza, A. R., \& Conterio, K. (1988). The plight of chronic self-mutilators. Community Mental Health Journal, 24, 22 - 30.

Goodman, R. (1997) The Strengths and Difficulties Questionnaire: A Research Note. Journal of Child Psychology and Psychiatry, 38, 581 - 586.

Hall, B., Elliott, J., \& Place, M. (2009). Self Harm Through Cutting - Evidence from a Sample of Schools in the North of England. Pastoral Care in Education, In Press.

Hawton, K., Hall, S., Simkin, S., Bale, L., Bond, A., \& Codd, S. (2003). Deliberate self-harm in adolescents: a study of characteristics and trends in Oxford, 1990-2000. Journal of Child Psychology \& Psychiatry, 44, 1191 - 1198.

Hawton, K., Rodham, K., Evans, E., \& Weatherall, R. (2002). Deliberate self harm in adolescents: self report survey in schools in England. British Medical Journal, 325, 1207 1211.

Kimber, B., Sandell, R., \& Bremberg, S. (2008). Social and emotional training in Swedish classrooms for the promotion of mental health: results from an effectiveness study in Sweden. Health Promotion International, 23, 134 - 143.

Klonsky, E. D., Oltmanns, T. F., \& Turkheimer, E. (2003). Deliberate self-harm in a non-clinical popultaion: Prevalence and psychological correlates. American Journal of Psychiatry, 160, 1501 - 1508.

Kolvin, I., Garside, R. F., Nicol, A. R., MacMillan, A., Wolstenholme, F., \& Leitch, I. M. (1981). Help Starts Here. The maladjusted child in the ordinary school. London Tavistock Publications.

Korner, A., Gerull, F., Stevenson, J., \& Meares, R. (2007). Harm avoidance, self-harm, psychic pain, and the borderline personality: life in a "haunted house". Comprehensive Psychiatry, 48, 303 - 308.

Mental Health Foundation (2006). Truth Hurts; Report of the National Inquiry into Self-harm Among Young People. London: Mental Health Foundation and Camelot Foundation.

Milnes, D., Owens, D., \& Blenkiron, P. (2002). Problems reported by self-harm patients: perception, hopelessness, and suicidal intent. Journal of Psychosomatic Research, 53, 819 822.

National Committee of Primary Mental Health Services (2005). The Competency and Capability Framework for Primary Mental Health Workers in Child and Adolescent Health Services (CAMHS). London: Care Services Improvement Partnership.

Neil, A. L., \& Christensen, H. (2009). Efficacy and effectiveness of school-based prevention and early intervention programs for anxiety. Clinical Psychological Review, 29, 208 - 215.

Raphael, H., Clarke, G., \& Kumar, S. (2006). Exploring parents' responses to their child's 
deliberate self-harm. Health Education, 106, 9 - 21.

Rones, M. \& Hoagwood, K. (2000). School-Based Mental Health Services: A Research Review. Clinical Child and Family Psychology Review, 3, 223 - 241.

Rosen, S., \& Collins, K. J. (1993). Six case studies depicting the deliberate self-harm syndrome. Curationis, 16, 50 - 55.

Ross, S., \& Heath, N. (2002). A study of the frequency of self-mutilation in a community sample of adolescents. Journal of Youth and Adolescence, 31, 67 - 77.

Roux, S. L., \& Overcash, J. (2008). Scratching the surface: addressing self-harm in adolescents. Nurse Practitioner, 33, 30 - 36.

Ruini, C., Ottolini, F., Tomba, E., Belaise, C., Albieri, E., \& Visani, D. (2009). School intervention for promoting psychological well-being in adolescence. Journal of Behavior Therapy \& Experimental Psychiatry, 40, 522 - 532.

Rutter, M., Maughan, B., Mortimore, P., Ouston, J., \& Smith, A. (1979). Fifteen Thousand Hours: secondary schools and their effects on children. London: Open Books.

Rutter, M., \& Smith, D. J. (1995). Psychosocial Disorders in Young People -- time trends and their causes. Chichester: John Wiley and Sons.

Shapiro, S. (2008). Addressing Self-Injury in the School Setting. Journal of School Nursing, 24, $124-130$.

Stallard, P., Simpson, N., Anderson, S., \& Goddard, M. (2008). The FRIENDS emotional health prevention programme: 12 month follow-up of a universal UK school based trial. European Child \& Adolescent Psychiatry, 17, 283 - 289.

Walsh, B. (2007). Clinical assessment of self-injury: A practical guide. Journal of Clinical Psychology, 63, 1057 - 1068.

Young, R., Sweeting, H., \& West, P. (2006). Prevalence of deliberate self-harm and attempted suicide within contemporary Goth youth subculture: longitudinal cohort study. British Medical Journal, 332, 1058 - 1061.

Zila, L. M., \& Kiselica, M. S. (2001). Understanding and counseling self-mutilation in female adolescents and young adults. Journal of Counseling \& Development, 79, 46 - 52. 